\title{
A study on the nonlinear behavior of crossing-fault buried pipelines using pushover analysis
}

\author{
Mahdi Shadab Far ${ }^{1, *}$, Nemat Hassani ${ }^{2}$, Reza Rasti ${ }^{2}$, Seyed J. Faraji ${ }^{3}$ \\ ${ }^{1}$ Department of Civil and Transportation Engineering, Hohai University, Nanjing, China \\ ${ }^{2}$ Department of Water and Environmental Engineering, Shahid Beheshti University, Tehran, Iran \\ ${ }^{3}$ Department of Landscape Architecture, Nanjing Forestry University, Nanjing, China \\ Email address: \\ mahdishadabfar@yahoo.com (M. Shadab Far), nemathassani@yahoo.com (N. Hassani), r_rasti@yahoo.com (R. Rasti), \\ f.jallalfaraji@yahoo.com (S. J. Faraji)
}

\section{To cite this article:}

Mahdi Shadab Far, Nemat Hassani, Reza Rasti, Seyed J. Faraji. A Study on the Nonlinear Behavior of Crossing-Fault Buried Pipelines Using Pushover Analysis. American Journal of Civil Engineering. Vol. 2, No. 6, 2014, pp. 152-157. doi: 10.11648/j.ajce.20140206.12

\begin{abstract}
Earthquakes can cause a lot of damages to buried pipelines. When pipelines are placed in a seismically active area, in addition to safety, performance, and environmental criteria, ground displacement hazards such as fault movements should be considered carefully. Therefore, the present study was aimed to evaluate the response of buried pipelines crossing ground deformation especially faulting based on nonlinear approaches. Considering the pipe as SHELL Element, soil as SOLID Element, and also non-linearity of material and geometry, several caseloads of buried pipelines crossing fault were modeled in the ABAQUS software. Then, all the models were analyzed in both tensile and compressive modes by Push-over analysis method. As a result, besides extracting the relationship between flexural moment and bending angle, the average of obtained curves were normalized and the standard five-line behavior curves were fitted to them. The developed curves can be simply used in any simplified modeling applications for assigning the plastic hinges to different types of pipelines.
\end{abstract}

Keywords: Buried Steel Pipelines, Pipe-Soil Interaction, SHELL Element, Pushover Analysis, Nonlinear Behavior Curves, Plastic Hinges

\section{Introduction}

Earthquake is one of the natural phenomena which can dramatically affect the physical environment and causes drastic changes in human life. Meanwhile, vulnerability assessment of phenomena affected by earthquake has a significant impact in reducing the probable losses [1].

One of the vital lifelines affected by the earthquake is underground pipelines which are increasingly utilized for transferring water, fuels, petrochemical materials, etc. Pipelines are considered as an important component of social systems and their damage can lead to environmental disasters and large economic losses. Moreover, pipelines located in the urban areas, due to the dense population and high-risk vulnerability of communities, have considerable importance [2]. In view of urban management system, damage to any of urban lifelines, that causes citizens to face risks, is recognized as a crisis factor and requires appropriate mitigation measures. This responsible attitude on one hand and scientific belief on the other hand has attracted great attention of researchers in this field, and caused the safety of buried pipelines to be considered as one of the significant issues in the field of earthquake engineering [3].

Because of linear structure and spreading in a wide area of ground, buried pipeline systems are exposed to a variety of geotechnical hazards, and therefore, are distinct from other kinds of engineering structures. In other words, since the buried pipelines are placed in a large area, the possibility of encountering the permanent ground displacement for these kinds of structures is higher than structures located in a small area or certain place [4]. Many of the water transmission lines, like the second branch of Tehran water pipeline which carries water from Bilaghan basin to Tehranpars refinery, crosses active fault in its path. Hence, Permanent Ground Displacement (PGD) hazards should be considered in both designing process of new pipelines and rehabilitation process of old pipelines [5].

Buried pipeline systems should rely on elasto-plastic material properties of pipe body to be yielded enough and prevent any probable rupture or damage during the earthquake [6]. In this study, under a given set of various 
conditions including four kinds of pipe material (table 1), two different pipe diameter $(0.4 \mathrm{~m}$ and $0.6 \mathrm{~m})$, three different crossing angle $\left(45^{\circ}, 60^{\circ}\right.$ and $\left.90^{\circ}\right)$ and three different fault displacement $(0.5 \mathrm{~m}, 1 \mathrm{~m}$ and $3 \mathrm{~m})$, the behavior of buried pipelines in relation to surface fault displacements is investigated.

\section{Different Hazards}

Seismic damages to buried pipelines can be due to Permanent Ground Displacement (PGD) hazards or wave propagation hazards. There have been cases where the pipe failure occurred simply because of the wave propagation hazards, but the failure of pipelines is usually due to a combination of these hazards. For example, O'Rourke mentioned that approximately half of the of pipe failure in 1906 San Francisco earthquake were due to the liquefaction and lateral spreading, while the other half of the failures occurred in a large area because of wave propagation hazard [4]. Therefore, it can be concluded that PGD failure usually occurs in limited area, by high failure rate, while wave propagation failure occurs in much larger area, by low failure rate [7].

\section{Pipe Failure Modes}

Pipelines crossing permanent ground deformation, apart from having plastic stress and strain in the pipe body, can suffer from two types of buckling including "beam buckling" and "local buckling" [8]. These failure modes are briefly discussed in the following.

\subsection{Beam Buckling}

Buckling is a structural instability in which the under pressure element changes from stable to unstable condition and experiences a sudden change in its configuration. Beam buckling of a pipeline is the same with the Euler buckling of a thin column in which the beam or pipe goes under a transverse (upward) displacement. In this type of buckling, since the relative displacement is distributed in a comparatively long length of element, there is not any severe strain on the pipe body. Therefore it seems that the beam buckling of pipe is better than the local buckling, because the pipeline is less likely to be ruptured.

\subsection{Local Buckling}

Local buckling of pipeline can be defined as a localized instability in the pipe body. Once the wrinkling of pipe body starts, all other geometrical distortion caused the deformation of the pipe to be more and more severe. Thus, the high bending strain in the pipe body will lead to cracking and leaking in the pipe wall. This is a common failure mode of steel pipes.

Remarkable point is that, in most cases, the local buckling and wrinkling of pipe body in the faulting zone is the main cause of breakdowns and failures. Therefore, in this paper, after modeling the entire length of the pipe by SHELL elements and considering the possibility of large geometrical deformations, attempts have been made to study the both mentioned failure modes in the pipe-fault crossing process.

\section{Analysis of Buried Steel Pipelines Crossing Fault}

Though the mentioned feature of buckling in pipelines is internationally recognized, a few earthquake resistant regulations include a chapter on the design, construction and performance of buried pipelines to resist earthquake, and more specific permanent ground displacement.

Some methods for analyzing buried pipelines subjected to fault movement have been proposed. Newmark and Hall considered only the tensile capacity of pipeline, and neglected the lateral soil restraint ratio. The pipeline deforms as a straight line AC (Figure. 1) [9].

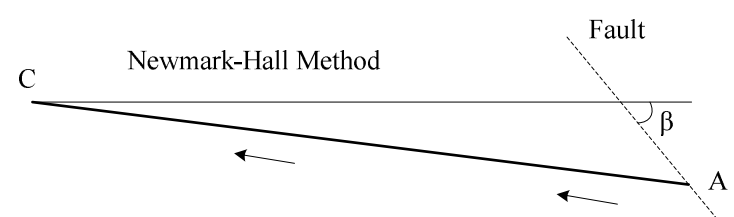

Figure 1. Newmark-Hall's Method

Kennedy et al. presented a different approach for the case of $\beta<90^{\circ}$, which divided the pipeline into two sections including a straight line section $\mathrm{BC}$, and an arch line section $\mathrm{AB}$ (Figure 2). Kennedy's method considered the lateral soil pressure on the pipeline which results in bending strain. Kennedy altered his method by considering the effect of uplift forces later [10].

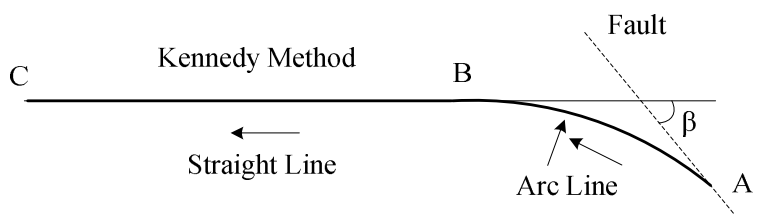

Figure 2. Kennedy's Method

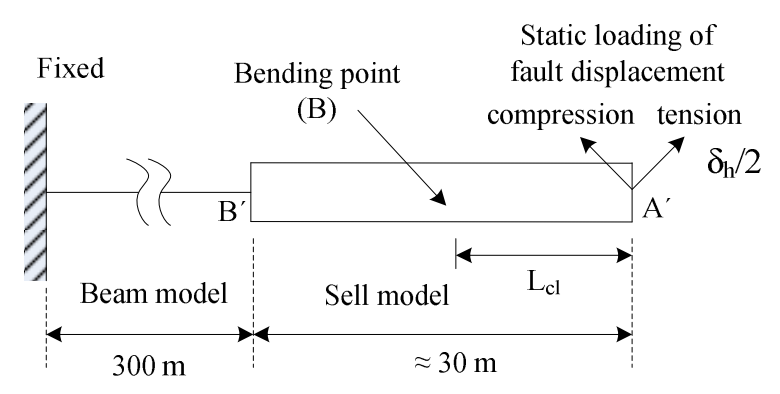

Figure 3. Takada, Hassani and Fukuda's method

Takada, Hassani, and Fukuda developed a simplified method which considered the section deformation of pipelines crossing faults [7]. They used a beam-shell hybrid 
model (Figure 3) to analyze the pipeline. The results eventuated a formula to calculate the compressive and tensile strain in pipeline crossing faults.

The approach of this article is developed based on the Takada, Hassani and Fukuda's method by three main differences:

- The effect of soil is considered.

- The entire pipe is modelled by SHELL element.

- Interaction of pipe and soil is defined.

\section{Modelling Details}

For doing the modeling process in this article, a length of pipeline in which the pipe bends and goes under the bending strain is calculated by Kennedy method, and the surrounded soil media, then, is modeled in this area [11]. In other words, the present paper includes the effect of soil on the pipeline. The soil is considered as SOLID element and the entire pipe as SHELL element (Figure 4).

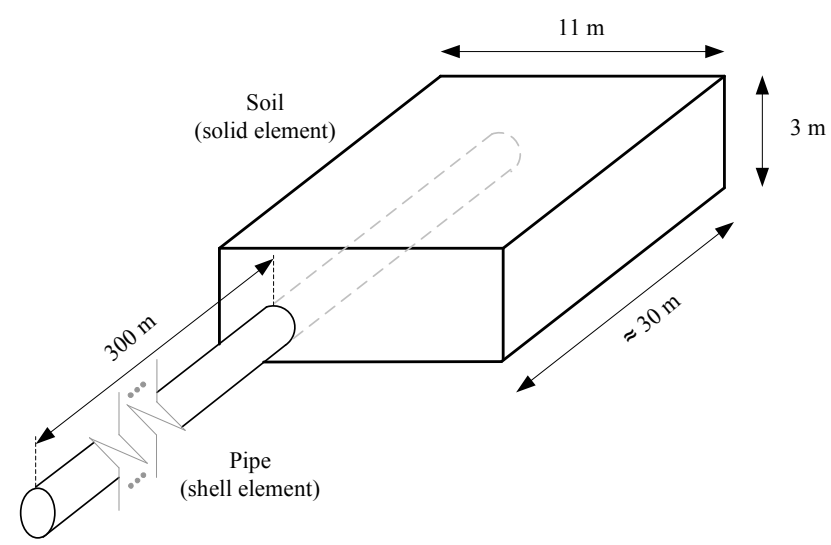

Figure 4. Modelling of pipe by SHELL element and soil by SOLID element

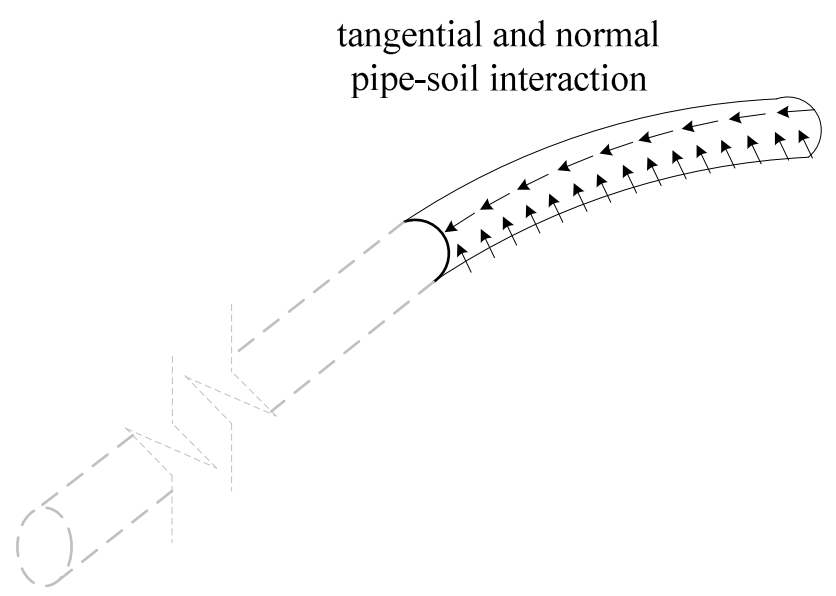

Figure 5. Modeling the pipe-soil interaction

The Drucker-Prager model was selected to simulate the constitutive law of soil. The property of soil was matched against Iranian code 2800 soil type II for structural seismic design [12]. The soil-pipe interaction was modelled by penalty method [13] that allows the relative movements of the surfaces when they should be attached (Figure 5).

Two types of steel pipes 400A and 600A are selected for the analysis (these are steel pipes which are used in Japan, and the numbers are the diameters in $\mathrm{mm}$ ). The stress-strain characteristics of pipe materials used in the analysis are presented in Figure 6 and Table 1.

Table 1. Stress-strain characteristics for different pipes

\begin{tabular}{lllll}
\hline Pipe type & $\boldsymbol{\sigma}_{\mathbf{y}}(\mathbf{M P a})$ & $\boldsymbol{\varepsilon}_{\mathbf{y}}(\%)$ & $\boldsymbol{\sigma}_{\mathbf{u}}(\mathbf{M P a})$ & $\boldsymbol{\varepsilon}_{\mathrm{u}}(\mathbf{\%})$ \\
\hline (a) For tension & & & & \\
400A & 344.12 & 0.17 & 446.20 & 5.00 \\
600A & 398.15 & 0.20 & 507.00 & 5.00 \\
(b) For compression & & & & \\
400A & 255.46 & 0.15 & 318.72 & 1.80 \\
600A & 292.24 & 0.20 & 441.30 & 1.00 \\
\hline
\end{tabular}

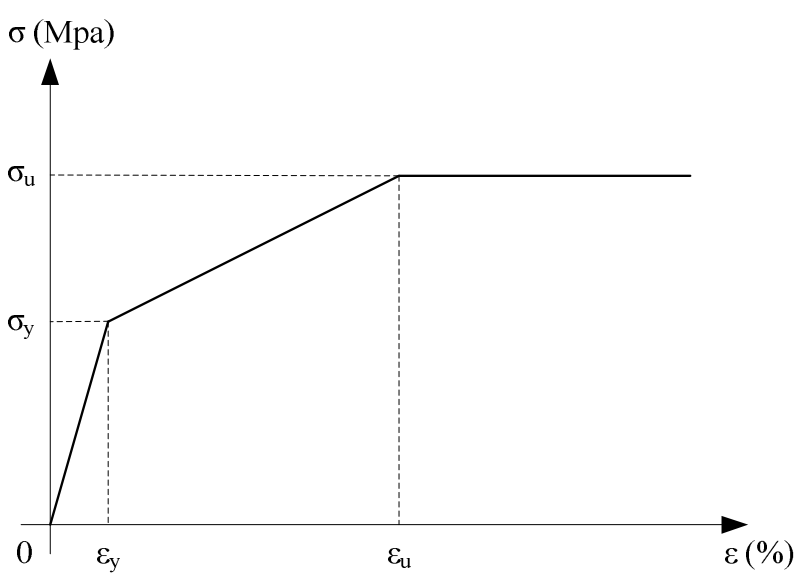

Figure 6. Stress-strain relation for the pipe

\section{Analytical Cases}

Under the reverse faults movement, the pipeline is analyzed for three displacements $(0.5 \mathrm{~m}, 1 \mathrm{~m}$ and 3 meters $)$ as well as three different crossing angles $\left(45^{\circ}, 60^{\circ}\right.$ and $\left.90^{\circ}\right)$ under compression and tension. These analytical cases are shown in Table 2.

\section{Nonlinear Behavior Curves}

After the modeling of all caseloads, the pipelines were analyzed by PUSH OVER method under faults movement with different conditions. Then, the relationship between the bending angle and bending moment were extracted for all analytical models. Figure 7 shows the results of the first and second analytical model (the first and second rows in Table 2) in both tension and compression. 
Table 2. Analytical cases

\begin{tabular}{|c|c|c|c|c|c|c|c|c|}
\hline & Type & $D_{\text {ext }}(m)$ & $\mathrm{t}(\mathrm{mm})$ & $\delta_{h}(m)$ & $\beta$ & $\Delta_{\mathbf{x}}(\mathrm{m})$ & $\Delta_{y}(m)$ & $\mathbf{L}_{\mathrm{cl}}(\mathbf{m})$ \\
\hline 1 & $400 \mathrm{~A}$ & 0.4 & 7 & 0.5 & 45 & 0.35 & 0.35 & 20 \\
\hline 2 & $400 \mathrm{~A}$ & 0.4 & 7 & 0.5 & 60 & 0.25 & 0.43 & 25 \\
\hline 3 & $400 \mathrm{~A}$ & 0.4 & 7 & 0.5 & 90 & 0.00 & 0.50 & 25 \\
\hline 4 & $400 \mathrm{~A}$ & 0.4 & 7 & 1.0 & 45 & 0.71 & 0.71 & 25 \\
\hline 5 & $400 \mathrm{~A}$ & 0.4 & 7 & 1.0 & 60 & 0.50 & 0.87 & 35 \\
\hline 6 & $400 \mathrm{~A}$ & 0.4 & 7 & 1.0 & 90 & 0.00 & 1.00 & 35 \\
\hline 7 & $400 \mathrm{~A}$ & 0.4 & 7 & 3.0 & 45 & 2.12 & 2.12 & 45 \\
\hline 8 & $400 \mathrm{~A}$ & 0.4 & 7 & 3.0 & 60 & 1.50 & 2.60 & 60 \\
\hline 9 & $400 \mathrm{~A}$ & 0.4 & 7 & 3.0 & 90 & 0.00 & 3.00 & 60 \\
\hline 10 & $600 \mathrm{~A}$ & 0.6 & 10 & 0.5 & 45 & 0.35 & 0.35 & 30 \\
\hline 11 & $600 \mathrm{~A}$ & 0.6 & 10 & 0.5 & 60 & 0.25 & 0.43 & 35 \\
\hline 12 & $600 \mathrm{~A}$ & 0.6 & 10 & 0.5 & 90 & 0.00 & 0.50 & 35 \\
\hline 13 & $600 \mathrm{~A}$ & 0.6 & 10 & 1.0 & 45 & 0.71 & 0.71 & 40 \\
\hline 14 & $600 \mathrm{~A}$ & 0.6 & 10 & 1.0 & 60 & 0.50 & 0.87 & 50 \\
\hline 15 & $600 \mathrm{~A}$ & 0.6 & 10 & 1.0 & 90 & 0.00 & 1.00 & 50 \\
\hline 16 & $600 \mathrm{~A}$ & 0.6 & 10 & 3.0 & 45 & 2.12 & 2.12 & 70 \\
\hline 17 & $600 \mathrm{~A}$ & 0.6 & 10 & 3.0 & 60 & 1.50 & 2.60 & 90 \\
\hline 18 & $600 \mathrm{~A}$ & 0.6 & 10 & 3.0 & 90 & 0.00 & 3.00 & 90 \\
\hline
\end{tabular}

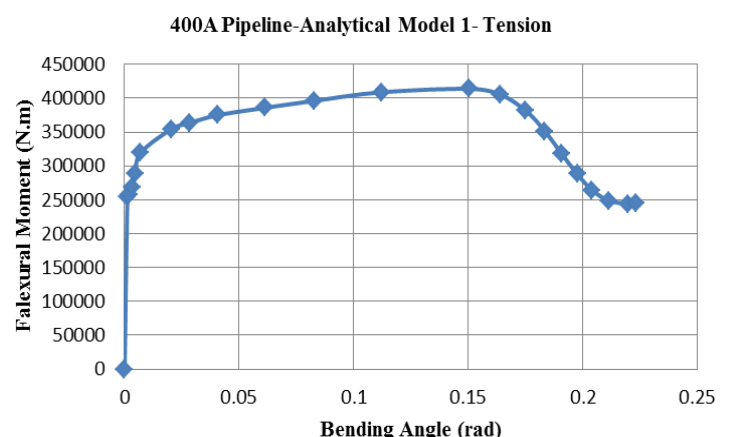

(a)

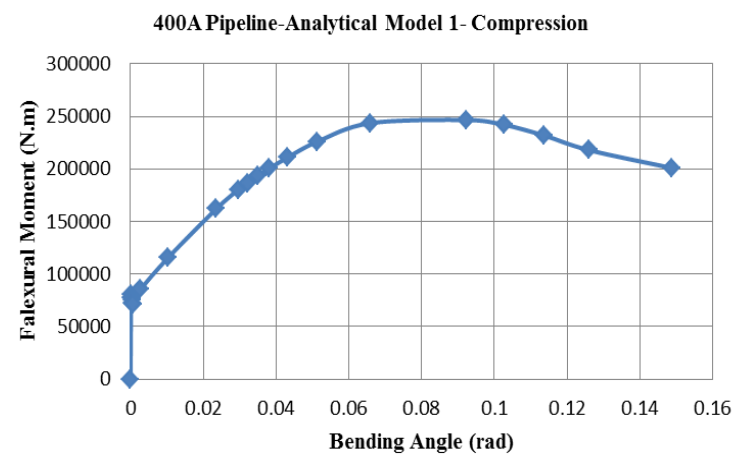

(c)

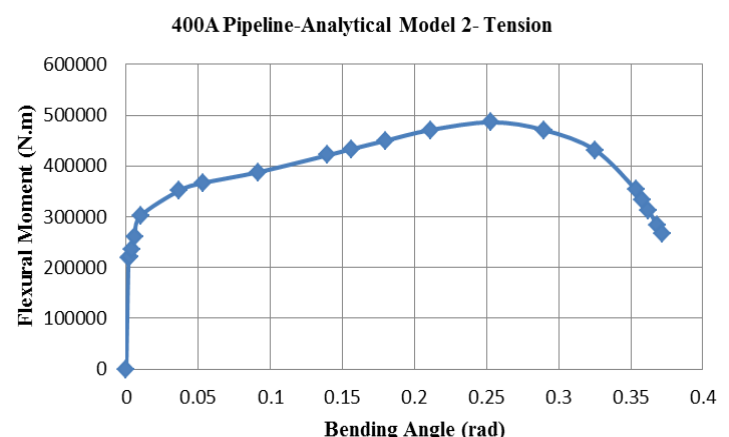

(b)

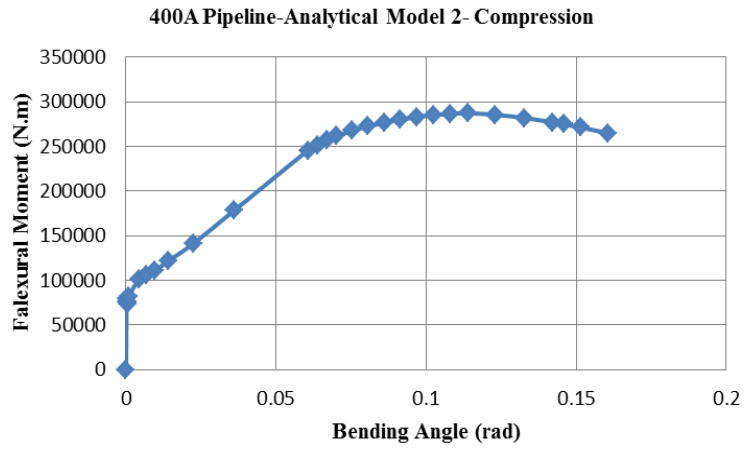

(d)

Figure 7. Flexural moment variations as a function of bending angle for 400A Pipeline (a) analytical model 1 in tension (b) analytical model 2 in tension (c) analytical model 1 in compression (d) analytical model 2 in compression

After the extraction of above mentioned curves, all tensile and compressive curves at $0.5 \mathrm{~m}, 1 \mathrm{~m}$, and $3 \mathrm{~m}$ were separately averaged and the mean curve was plotted. By normalizing these curves to $\mathrm{M}_{\mathrm{y}}$ and interpolating a standard five-line behavior curve to them, the following curves were obtained (Figures 8a to 8f). Geometrical coordinates of the presented five-line curves are shown in Table 3.

These obtained curves can be used for nonlinear analysis of buried continues pipeline crossing fault in any software which can assign nonlinearity of materials as plastic hinges to beam elements [14]. To perform such an analysis, it is enough to model a beam as pipe and some equivalent springs 
as soil. Plastic hinges should be assigned to pipe between

curves.

equivalent springs in faulting zone by the proposed behavior

Table 3. Normalized five-line curves for different fault's displacements in tension and compression

\begin{tabular}{lllllllllllll}
\hline \multicolumn{2}{l}{ Tension $\boldsymbol{\delta}=\mathbf{0 . 5} \mathbf{~ m}$} & \multicolumn{2}{l}{ Tension $\boldsymbol{\delta}=\mathbf{1} \mathbf{~ m}$} & \multicolumn{2}{c}{ Tension $\boldsymbol{\delta}=\mathbf{3} \mathbf{~ m}$} & \multicolumn{2}{c}{ Compression $\boldsymbol{\delta}=\mathbf{0 . 5} \mathbf{~ m}$} & \multicolumn{2}{c}{ Compression $\boldsymbol{\delta}=\mathbf{1} \mathbf{~ m}$} & \multicolumn{2}{c}{ Compression $\boldsymbol{\delta}=\mathbf{3} \mathbf{~ m}$} \\
\hline $\boldsymbol{\theta}(\mathbf{r a d})$ & $\mathbf{M} / \mathbf{M y}$ & $\boldsymbol{\theta}(\mathbf{r a d})$ & $\mathbf{M} / \mathbf{M y}$ & $\boldsymbol{\theta}(\mathbf{r a d})$ & $\mathbf{M} / \mathbf{M y}$ & $\boldsymbol{\theta}(\mathbf{r a d})$ & $\mathbf{M} / \mathbf{M y}$ & $\boldsymbol{\theta}(\mathbf{r a d})$ & $\mathbf{M} / \mathbf{M y}$ & $\boldsymbol{\theta}(\mathbf{r a d})$ & $\mathbf{M} / \mathbf{M y}$ \\
\hline 0 & 0 & 0 & 0 & 0 & 0 & 0 & 0 & 0 & 0 & 0 & 0 \\
0.006 & 1 & 0.008 & 1 & 0.01 & 1 & 0.006 & 1 & 0.008 & 1 & 0.01 & 1 \\
0.09 & 1.4 & 0.12 & 1.6 & 0.32 & 1.63 & 0.14 & 1.45 & 0.25 & 1.6 & 0.28 & 1.7 \\
0.09 & 0.9 & 0.12 & 0.9 & 0.32 & 0.9 & 0.14 & 0.9 & 0.25 & 0.9 & 0.28 & 0.9 \\
0.11 & 0.9 & 0.16 & 0.9 & 0.5 & 0.9 & 0.18 & 0.9 & 0.334 & 0.9 & 0.42 & 0.9 \\
\hline
\end{tabular}

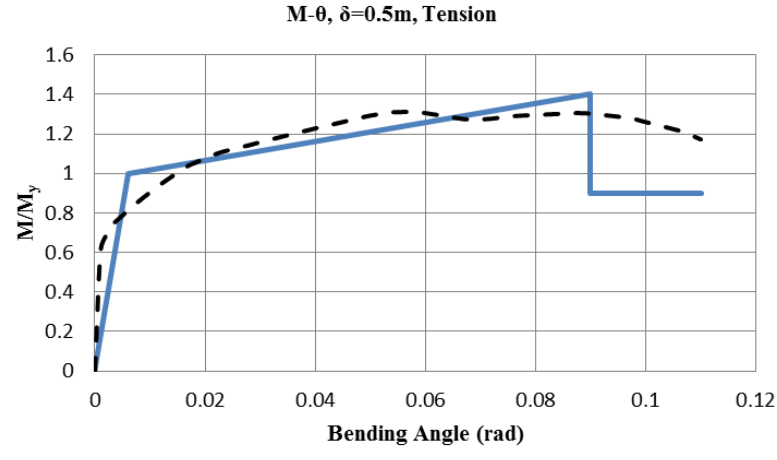

(a)

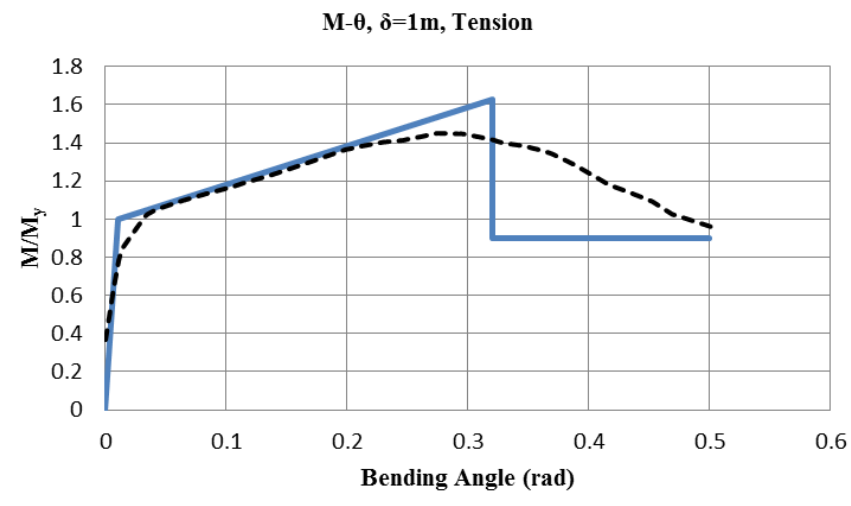

(c)

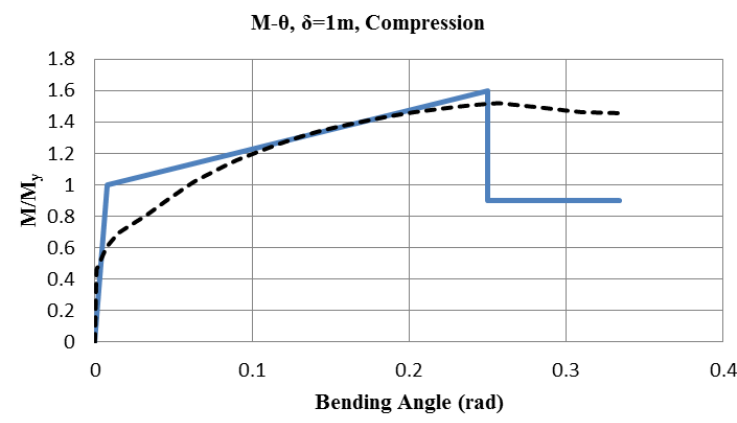

(e)

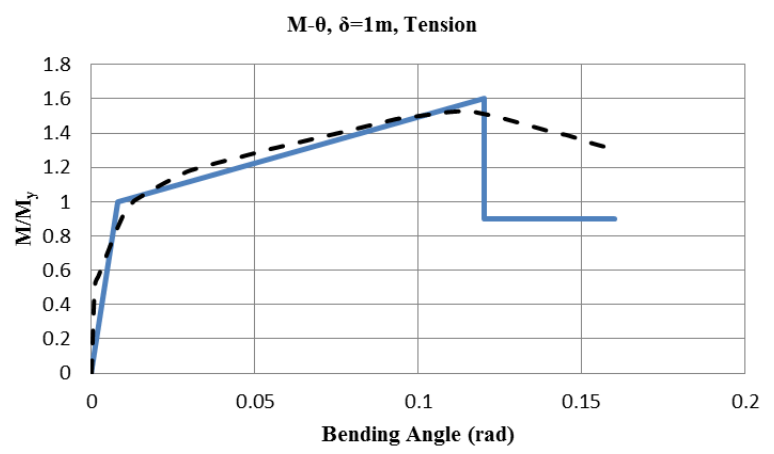

(b)

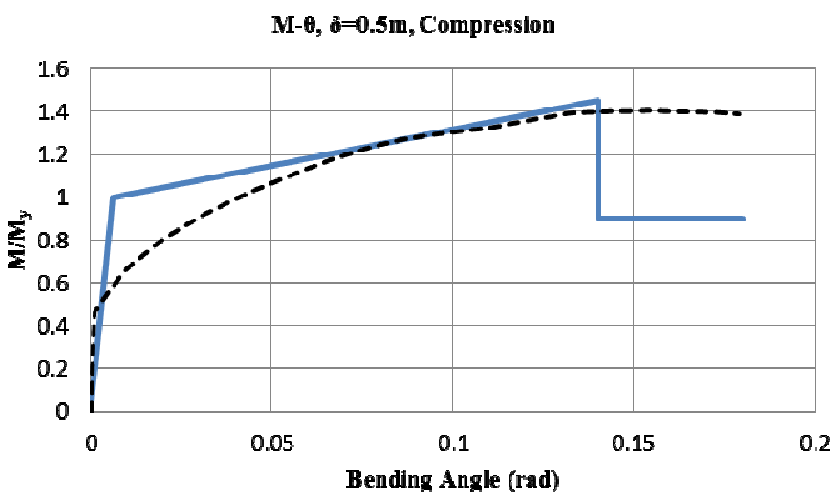

(d)

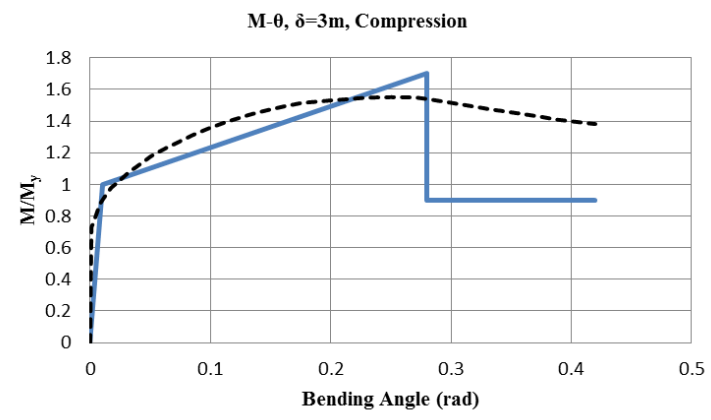

(f)

Figure 8. Normalized five-line curves for (a) $\delta=0.5 \mathrm{~m}$ in tension, (b) $\delta=1 \mathrm{~m}$ in tension, (c) $\delta=3 \mathrm{~m}$ in tension, (d) $\delta=0.5 \mathrm{~m}$ in compression, (e) $\delta=1 \mathrm{~m}$ in compression, (f) $\delta=3 m$ in compression

Remarkable point is that modeling of pipe by SHELL element and nonlinear analysis of pipeline crossing fault is a very time-consuming and difficult task and cannot simply be performed. But as mentioned, using the five-line behavior curves proposed in this article, the pipe-fault crossing problem can be modeled and analyzed by BEAM element. In 
this case, however, pipe is modeled by BEAM element, but since the nonlinear behavior curves are already extracted by SHELL elements model, the pipe shows SHELL behavior.

\section{Conclusion}

Looking at the events occurred in our seismically active world, this fact becomes apparent that paying attention to the earthquakes and existing faults surrounding the lifeline structures such as buried pipelines has become a unique necessity and caused people to realistically encounter to this important matter.

Nonlinear analysis of buried pipelines crossing fault is a time-taking and expensive analysis especially by considering SHELL elements. So, it seems necessary to propose a simple and accurate method for this issue.

In this paper, after the modeling of pipe by SHELL element and the surrounding soil by SOLID element, the nonlinear static analysis was used to analyze the pipe-fault crossing problem. Relation between the flexural moment and the bending angle was extracted from the analytical results and the averages of obtained curves were normalized to My. Then, in order to predict the non-linear behavior of pipeline, a standard five-line curve was fitted to the normalized curves for each fault displacement. Using the proposed curves in this paper, after modeling the pipe by BEAM element and assigning the plastic hinges to the pipe in the faulting zone, the push-over analysis of pipe-fault crossing problem can be simply performed without any certain difficulties or problems.

Regarding the assumptions and results of this study, it seems necessary to mention a few points:

1. The results of this paper have been obtained by assuming only one type of soil (soil type 2 code 2800) [12]. If the pipe is placed in a different type of soil, using these curves will result in a percentage of error.

2. The analysis in this paper conducted on continuous steel pipes; consequently, the results should only be used for analyzing this type of pipelines.

3. Pipes buried in higher depth and pipes with special sizes were not discussed in this article, and should separately be studied.

\section{References}

[1] S. J. Faraji, Q. P. Zhang, M. Shadab Far, H. Kordestani, and S. Y. Faraji, "A Simplified Method for the Seismic Analysis of Urban Transportation Tunnels," International Journal of Geology, vol. 8, pp. 4, 2014.
[2] M. Shadab Far, Q. Zhang, R. Rasti, and S. J. Faraji, "Seismic Analysis of Urban Water Supply Systems (Case Study: Qazvin City, Iran)," International Journal of Geology, vol. 8, pp. 13, 2014.

[3] T. Ariman, and B. J. Lee, "Tension/Bending Behavior of Buried Pipelines Under Large Ground Deformation in Active Faults," Tenth World Conference on Earthquake Engineering (1992), Balkerna, Rotterdam.

[4] M. J.O'Rourke, "Buried Pipelines," Handbook of earthquake engineering: W. F. CHEN Hawaii University, 2000.

[5] M. Liu, Y. Wang, and Z. Yu, "Response of pipelines under fault crossing," 18th International Offshore and Polar Engineering Conference (2008), Vancouver, Canada.

[6] A. Liu, S. Zhang, Y. Hu, and X. Li, "A method for analyzing response of buried pipeline due to earthquake fault movement," Earthquake Engineering and Engineering Vibration, no. 2, pp. 6, 2002.

[7] S. Takada, N. Hassani, T. Tsuyoshi, and R. Ozaki, "A new proposal for simplified seismic response analysis of pipes in ground with inclined bed-rock," Twelfth World Conference of Earthquake Engineering (2000), Auckland, New Zealand, pp. 8.

[8] N. Hassani, M. Shadab Far, and H. Kordestani, "Effects of Crossing Angle on the Behavior of Buried Steel Pipelines Crossing Fault," International Journal of Applied Mechanics and Materials, vol. 351-352, pp. 7, 2013.

[9] American Lifeline Alliance (ALA), "Seismic guidelines for water pipelines," Equivalent Static Method, American Society of Civil Engineering (ASCE), 2005.

[10] R. P. Kennedy, and R. H. Kincaid, "Fault crossing design for buried gas oil pipelines," Proceedings of ASME-PVP Conference (1983), Oregon, USA, pp. 9.

[11] R. P. Kennedy, and A. R. Chow, "Fault movement effects on buried oil pipeline," ASCE Journal of Transportation Engineering, vol. 103, pp. 17, 1986.

[12] "Iranian Code of Practice for Seismic Resistant Design of Building (Standard No. 2800-05) " soil type classification, Iranian Building and Housing Research Centre, 2005.

[13] Abaqus Software (Version 6.10), documentation collection, getting started with Abaqus, section 12.9, "defining contact in Abaqus/Explicit"

[14] R. Rasti, and M. Shadab Far, "Providing base reaction coefficient for different soil types according to Code 2800," International conference on water and wastewater (2011), Tehran, Iran, pp. 9. 